\title{
Papers
}

\section{The Relationship of Annual Giving and Endowment Payout to Future Tuition Dependency at Private Master's Universities}

Received (in revised form): May 12, 2003

\section{Vincent M. Maniaci}

has been the Vice President for Institutional Advancement at Bellarmine University since 1997. He also teaches in Bellarmine's undergraduate core program and has an appointment to the University's Rubel School of Business where he teaches in the MBA program. This paper was adapted from his doctoral dissertation at the University of Pennsylvania GSE. He received the Grenzebach Award for Outstanding Dissertation in the field of Philanthropy for Education in 2003.

\section{Rob Poole}

graduated from Texas A\&M with a BS in Economics and was commissioned in the Marine Corps, where he was stationed all around the world. Returning to the United States, he went to USC for a master's degree in systems management. Later he obtained a Ph.D. in operations management and has taught at several schools, including the University of North Texas, Central Missouri State University, and Bellarmine University, where he led the MBA program. He researches and consults on a variety of interests including education reform, fund raising and other applied process improvements.

\section{Thomas L. Wilson}

is Associate Professor of Psychology at Bellarmine University. He is an experimental psychologist who focuses his teaching and research in the areas of learning, memory, and cognition. He serves as advisor to students interested in pursuing traditional academic careers in psychology and regularly teaches the major foundation courses in experimental and statistical methods in behavioral science for the undergraduate major. Dr. Wilson's research interests include the cognition of mental comparison, questions of consciousness, and language comprehension.

\author{
Author's Contact Address: \\ Vincent M. Maniaci \\ Vice President for Institutional Advancement \\ Bellarmine University \\ 2001 Newburg Road \\ Louisville, KY 40205, USA \\ Tel: +15024528328 \\ Fax: +1 5024528337 \\ Email: vmaniaci@bellarmine.edu
}

\author{
Abstract \\ Setting the annual fund goal and raising \\ money for restricted rather than \\ unrestricted support has become a major \\ bone of contention at many private \\ universities. Often at issue are the integrity
}


of the budget process and the tension between the central administration and program and departments that feel that their potential for gift support to their restricted purposes are being cannibalized by the priority placed on unrestricted fund raising. Further tension is created by the sense that the central administration is guilty of excessive or inefficient spending. To date there has been no guideline provided to determine what the goal for unrestricted fund raising (the annual fund) should be. Moreover, there has been no empirical study to determine whether the excessive reliance on fund raising for annual operations has any long-term detrimental effect. This paper addresses the need to consider the annual fund goal as a component of long-term strategic planning and offers a guideline or benchmark based on overall revenue dependency for establishing the annual fund goal. The paper also examines the relationship different levels of endowment payout and annual fund have on tuition dependency after a tenyear period by using an analysis of variance.

\section{Keywords:}

annual fund, tuition dependency, strategic planning, operating budgets, financial vulnerability, resource allocation, endowment payout

\section{Introduction}

For nearly twenty years, the authors have been frustrated and bewildered by the common practice of many small private institutions to set their annual fund goals based on short-term financial exigency rather than long-term strategic planning. The authors have speculated that this practice hinders overall fund raising, increases financial vulnerability, creates internal tension, and perpetuates a lack of discipline in the budget process. However, they have not had a test, or a metric to test, in support of their argument, until now.

In the 1980s and 1990s, many nonprofit institutions realized excess revenues that could be diverted into construction, financial aid, or endowment. Institutions were able to increase tuition revenue and divert the balance into endowment. This practice allowed many boards and administrations to avoid two difficult tasks: raising endowment and annual giving for current operations and controlling spending. ${ }^{1}$

Capital markets have since slowed. Inevitably, higher education has come to rely on undergraduate tuition as its primary income stream. ${ }^{2}$ This reliance on tuition renders the smaller private institutions, with meager endowments, especially vulnerable to changes in the student market. Market competition for enrollment and fund raising favor the more selective, better endowed, and larger institutions. Without careful strategic planning supported by prudent fiscal management, many smaller private institutions, currently living on the edge, may not survive. According to data from the National Center for Education Statistics, 502 nonprofit colleges closed from 1969-70 to 2000-01, including 227 that have closed since 1990-91. Among the 227 to close since the 1990s, 215 were private. ${ }^{3}$ This trend is likely to continue, and perhaps escalate, if academic decision makers fail to pay attention to the relationship between reliance on fundraising revenue for operating support and the impact it has on financial vulnerability.

For many private master's institutions, exigency, rather than strategic planning, drives the practice of setting the annual 
fund-raising goal for unrestricted current operations. The authors identify a benchmark for setting the annual fund goal for current operations. Further, they argue that exceeding the benchmark for fund raising for current operations will lead to greater financial vulnerability as determined by an increase in tuition dependency.

\section{Review of the Literature}

While there is much speculative writing on fund raising, there is virtually nothing on the impact of tying the annual fund into long-term strategic planning. The closest literature is related to strategic planning and studies on financial vulnerability for nonprofits. Most importantly, Massy related mission and managing budget efficiency to long-term planning and endowment. ${ }^{4}$ Mission, vision, strategic planning, and budgeting are critical to the well-being of institutions in higher education. Unfortunately, many institutions do not plan for these or integrate them effectively. Strategic planning must start with the charter of the organization and address its internal and external environment. Effective planning requires expenditures to be prioritized and aligned with revenues according to mission and return on investment. The budget is the way to operationalize the strategic planning of the institution.

The strategic decision makers must properly define what the institution is and what it is not. The mission of the institution includes consideration of programs, faculty, and students. The programs can be undergraduate or graduate (master's or even doctoral granting). The faculty can be predominantly full-time or mostly adjuncts. The range of programs and faculty affects cost significantly. The students recruited can be international, national, regional, or local in scope. Most institutions have some sort of strategic planning process to manage these variables. Through Massy's framework for sources of operating revenue, a very simple equation is developed for private master's institutions: $\mathrm{Ex}=\mathrm{AF}+\mathrm{EP}+\mathrm{NT}$, where the expenditures expressed in the operating budget are equal to the revenues raised by the annual fund plus endowment payout plus net tuition.

The equation is derived from the following analysis. By definition, a nonprofit organization will have zero profit, thus TC $=$ TR (total cost $=$ total revenue). This can be rewritten as $\mathrm{Ex}=\mathrm{AF}+\mathrm{EP}+\mathrm{NT}+\mathrm{AR}$ (expenditures $=$ annual fund + endowment payout + net tuition + auxiliary net revenue, which are the major sources of revenue for a mastergranting institution). The total costs for an institution are the expenditures expressed in the operating budget. Revenue from research indirect cost and government subsidy are not applicable to most private master's institutions. Net revenue from auxiliary enterprise at private master's institutions tends to be insignificant in relation to the total operating budget and, therefore, was not included in the study. Thus, the operating budget is stated as $\mathrm{Op}=\mathrm{AF}+\mathrm{EP}+\mathrm{NT}$.

Dividing each side of the equation by the operating budget provides a measure of dependency of the budget for each of the revenue sources. $\mathrm{Op} / \mathrm{Op}=[\mathrm{AF}+\mathrm{EP}$ $+\mathrm{NT}] / \mathrm{Op}$ or $1=\mathrm{AF} / \mathrm{Op}+\mathrm{EP} / \mathrm{Op}+$ $\mathrm{NT} / \mathrm{Op}$, where AF/Op is dependency of the institution on annual fund raising, $\mathrm{EP} / \mathrm{Op}$ is dependency on endowment payout, and NT/Op is the dependency on 
net tuition. Only the exceptional institution is not concerned with its degree of tuition dependency.

The tuition rate set by the board can be low or high depending upon the market in which the institution finds itself. A key indicator of the ability of the board to set the tuition rate is determined by how much of the total revenue is provided by tuition, which is referred to as the tuition dependency of the institution.

The costs of higher education are essentially borne by three revenue entities: students/parents, government, and philanthropists. Students/parents pay tuition, the governments subsidize the cost of public schools, and philanthropists donate money to the annual fund or to endowment, some percentage of which is available for spending each year. "The sharing and shifting of these costs is essentially a zero sum game, in which a lessening of the burden upon revenue from one party must be compensated either by a reduction of underlying costs or by a shift of the burden to another party." 5

A common, but not advisable, practice of the budget process for those institutions with a current spending preference is to determine total revenues and expenditures for the coming year and to use unrestricted gift income (also referred to as the annual fund) to make up the difference. There are a number of reasons for this practice.

Tuition is the largest source of revenue. The actual number of students enrolled is realized in early fall. Further, tuition revenue is set in the fall for the entire year, with the exception of student attrition or new transfers in the spring. Endowment revenue is predetermined, usually based on a spending policy that includes a three to five year smoothing rate. Therefore, the annual income from endowment and tuition is much easier to accurately project.

Gift income is not fully received until the end of the year. This gives the institution (read the development office and the board of trustees) a longer time to reach their gift objectives. Further, because the actual number for tuition revenue is known in the fall, there is a better indication of how hard or soft the annual fund goal must be, and the goal can be adjusted accordingly. Finally, because fund raising is speculative and funding sources are theoretically infinite, decision makers are more comfortable using the annual fund goal to fill the gap in the budget process. ${ }^{6}$ This reduces the accountability of the decision makers to properly decide upon a proper budget in the first place. In this situation the annual fund is used to plug a gap in the operating budget by virtue of afterthought rather than as a strategic factor.

\section{Strategic Time Horizon}

Strategic decision makers must constantly juggle current and future expenses. The mission that is acceptable today may not be tomorrow. The academic programs of today are not the needs of future students and programs cannot be developed overnight. Hiring appropriate faculty can take years. Regardless of whether institutions spend money now or save for the future, they cannot expect to thrive without growth. Growth in the private sector is not merely desirable, it is necessary. ${ }^{7}$ In a university context of diminishing resources, the greatest risk is to stop growing, to survive by indiscriminately underfinancing all fields of activity. ${ }^{8}$ 
Universities can only regress by attempting to maintain the status quo. Universities must constantly evaluate their current mission and plan for the future. They must evaluate whether they have the proper mix of programs and the right kind of faculty. Changes in the dependency of the school on tuition for revenues are strong indicators of institutional ability to succeed in the long run.

Massy provides a framework for longterm mission accomplishment through resource allocation by looking at whether revenue is better spent for current use or future use. ${ }^{9}$ The question of whether institutions should have a current or future orientation for allocating resources is particularly acute when there is surplus revenue. In good years, or with careful financial strategizing, institutions may incur surplus revenue. There are three ways of handling surplus revenue:

1. Retain in current operations

2. Transfer to quasi-endowment

3. Transfer to other funds to establish balances.

Lenington favors sweeping all excess revenue into quasi-endowment because it results in zero balance, and strengthens the balance sheet by consolidating reserves. Fund balances in the quasi endowment facilitate calculations of average endowment per student, which helps when applying for a bond issue. Further, spending quasiendowment might negate the need to run a deficit in the current fund. ${ }^{10}$

Lenington goes on to say:

Institutions that accumulate a large portion of their endowment in the form of quasi endowment have the opportunity to become less tuition dependent. Benefactors of the institution should be encouraged to give unrestricted funds that can either be used for current operations or added to the quasi endowment. In addition, management should be encouraged to incur excess revenues on a regular basis to accumulate quasi endowment for reinvestment at a later time. ${ }^{11}$

\section{Vulnerability}

Increasing revenue at an institution with a poor mission and strategic plan or at one with a poor budget process may work temporarily, but eventually these weaknesses will start to affect program offerings and enrollment. At this point it should become increasingly difficult to increase revenue. The institution must reevaluate its mission, strategic plan, and budget process, or risk increasing vulnerability and failure.

Metaphorically, consider the family that manages to meet its expenses by paying the minimum monthly limit on credit cards and increasing that limit each month. Instead of controlling costs, the family opts to gradually increase its monthly spending and go further into debt. This practice reduces the family capacity to save for the future. It also is unhealthy because it creates disincentive for a more disciplined budget process. At a certain point, the family finances become unstable when the family reaches the point where it can no longer afford to make the minimum monthly payment even though its expenses continue to rise. The dependency on work-related income without savings can lead to bankruptcy or a situation whereby the family can no longer meet its financial objectives should that work income shrink even temporarily. 
An institution that allows its annual expenses to arbitrarily increase and opts to meet them by increasing the amount of funds raised for current spending, reduces its ability to raise money for future needs or emergencies. Thus it ends up relying more heavily on fund raising and tuition and less on the more stable revenue source from endowment payout.

Several researchers have examined nonprofit organizations to identify factors that predict or indicate financial vulnerability. Tuckman and Chang developed a model using quintiles to rank organizations in order of financial vulnerability. ${ }^{12}$ In this model an organization was defined as financially vulnerable if it is likely to cut back its service offerings when it experienced a financial shock. They identified four indicators that signaled a tendency toward financial vulnerability:

\section{Inadequate equity balances defined as} debt to equity ratio,

2. Revenue concentration,

3. Lean administrative costs defined as insufficient support for operations,

4. Low operating margins.

More recently, Greenlee and Trussel used those financial indicators to determine the probability of an organization becoming financially vulnerable. Greenlee and Trussel extended Tuckman and Chang's research by using methodologies of the profit sector to predict distress by charities. They defined a financially troubled charity as "one that reduces program expenditures in each of three consecutive years." They found a significant relationship between financial distress and three of the four variables adapted by Tuckman and Chang. Only inadequate equity balances were not found to be statistically significant. ${ }^{13}$

Each of the three indications of vulnerability is related and has a compounding effect on each other. For universities, revenue concentration is most commonly found through tuition dependency. The other two significant indicators, lean administrative cost and low operating margins, compound the negative impact of revenue concentration in the form of tuition dependency in higher education. Lean administrative costs in this context are a reflection of insufficient support for operations, while low operating margins point to inadequate net revenue or low pricing. Each of these factors exacerbates the problem of revenue concentration in the form of tuition. The low operating margins may result from high tuition discounting deemed necessary to attract students. This leaves the institutions with insufficient revenue for operations, hence overly lean administrative costs

The question is how much tuition dependency is too much. The tests below will establish guidelines for determining how much revenue should be generated from the annual fund and how much from endowment payout by establishing a relationship between the level of reliance from these revenue sources and future tuition dependency.

RQ1: Is the change in tuition dependency from 1992 to 2001 a function of the annual fund expenditure ratio in 1992?

RQ2: Is the change in tuition dependency from 1992 to 2001 a function of endowment spending to expenditure ratio in 1992? 
The authors investigate how present decisions related to budget and revenue allocation impact tuition dependency in the long run. In particular, they explore the relationship between the level of annual fund raising for operations and endowment payout to tuition dependency.

\section{Methodology}

The Voluntary Support of Education report was used as a database to test private master's institutions in 1992 and 2001. ${ }^{14}$ 2001 was the most recent data and 1992 provided data from 10 years earlier. The tenyear difference is deemed sufficient time for changes in programs to be noticed. Private schools were chosen to eliminate the effect of government subsidy and doctoralgranting institutions were ruled out because of the additional cost of research in their budgets. Master's-granting schools have a wide range of programs. There were 98 institutions used in the study.

\section{Variables}

There were two independent variables each measured in four categories. One variable was the ratio of the annual fund to the operating budget. The ratio of the annual fund to the operating budget is defined as the percentage of the operating budget provided by giving to the annual fund in a fiscal year. The second was the ratio of the endowment payout to the operating budget. This ratio is defined as the percentage of the operating budget provided by endowment payout in a fiscal year. The four categories for both factors were defined as follows:

$\begin{array}{ll}\text { Category } 1 & 0 \text { to } 1.99 \% \\ \text { Category } 2 & 2 \text { to } 3.99 \% \\ \text { Category } 3 & 4 \text { to } 5.99 \% \\ \text { Category } 4 & 6 \% \text { and above }\end{array}$

The dependent variable was the change in tuition dependency for institutions over a ten-year mark. Tuition dependency is defined as the percentage of the total operating budget provided by net tuition in a fiscal year. We looked at the tuition dependency for both 1992 and 2001, reasoning that ten years provided enough time for the factors to impact tuition dependency. To compute change in tuition dependency over the ten-year period, we subtracted tuition dependency in 2001 from the value in 1992; thus, an increase in tuition dependency is reflected in the following analysis as a negative value.

Research question 1 was: is the change in tuition dependency from 1992 to 2001 a function of the annual fund to expenditure ratio in 1992? This was tested with ANOVA.

Hypothesis 1 was: there will be a significant main effect of annual fund expenditure ratio on tuition dependency with a greater increase in tuition dependency for institutions with high annual fund expenditure ratio in 1992 than for institutions with low annual fund to expenditure ratios in 1992.

In order to address research question 1, tuition dependency was analyzed in a oneway analysis of variance using the four categories of annual fund to expenditure ratios in 1992 as the factor. Results indicated a main effect for annual fund to expenditure ratio category, $F(3,94)=4.59$, $p<0.01$. As shown in Figure 1, institutions at the highest level of annual fund to expenditure ratio showed a small increase in tuition dependency $(-0.34 \%, n$ $=19$ ), while institutions at the lowest level of annual fund to expenditure ratio showed a marked decrease in tuition dependency $(3.55 \%, n=29)$. The largest 


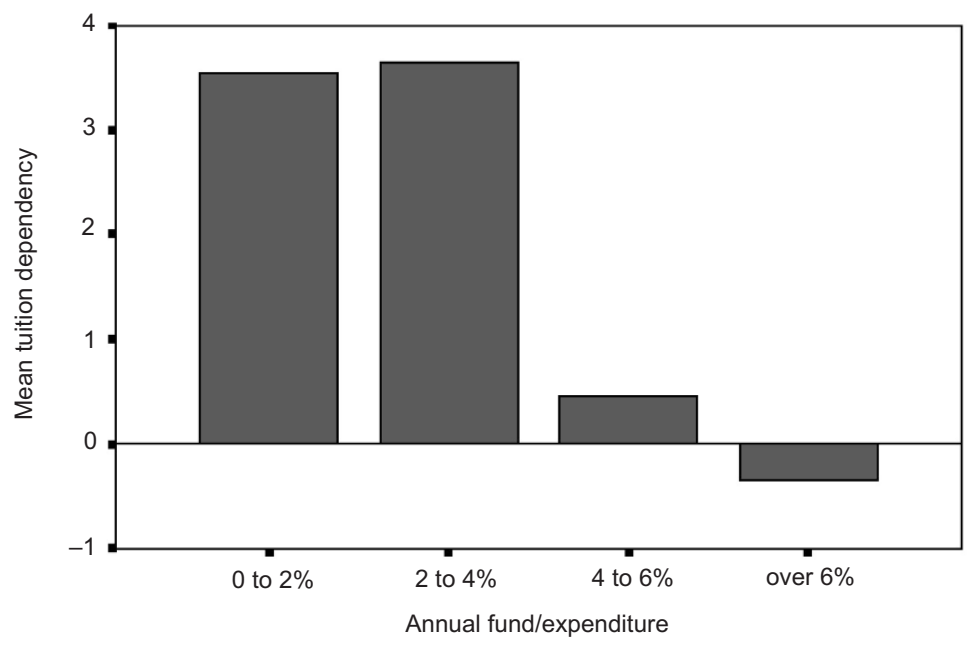

Figure 1: Tuition dependency as a function of annual fund to expenditure ratio

difference in the tuition dependency function occurs between institutions with annual fund to expenditure ratios between 2 and 4 per cent $(3.66 \%, n=36)$ and annual fund to expenditure ratios between 4 and 6 per cent $(0.45 \%, n=14)$.

Research question 2 was: is the change in tuition dependency from 1992 to 2001 a function of the endowment spending to expenditure ratio in 1992? It was tested with ANOVA.

Hypothesis 2 was: there will be a significant main effect of endowment spending to expenditure ratio on tuition dependency in 2001 in which institutions with high endowment spending to expenditure ratio in 1992 experience a decrease in tuition dependency relative to institutions with low endowment spending to expenditure ratios in 1992.

In order to address research question 2, tuition dependency was analyzed in a oneway analysis of variance using the four categories of endowment spending to expenditure ratios in 1992 as the factor.
Results indicated a main effect for endowment spending to expenditure ratio category, $F(3,94)=2.908, p<0.04$. As shown in Figure 2, institutions at the highest level of endowment spending to expenditure ratio showed a large decrease in tuition dependency $(5.25 \%, n=15)$, while institutions at the lowest level of endowment spending to expenditure ratio showed only a slight decrease in tuition dependency $(1.07 \%, n=29)$. The decreasing tuition dependency function appears as a step function of the endowment spending to expenditure ratio categories, with institutions between 2 and 4 percent $(1.83 \%, n=34)$ and institutions between 4 and 6 per cent $(3.1 \%, n=20)$ decreasing in their dependency on tuition.

\section{Findings and Implications}

The findings were that institutions that relied on 4 per cent or more of their operating revenue from annual funds had an increase in tuition dependency ten years later. In contrast, institutions that 


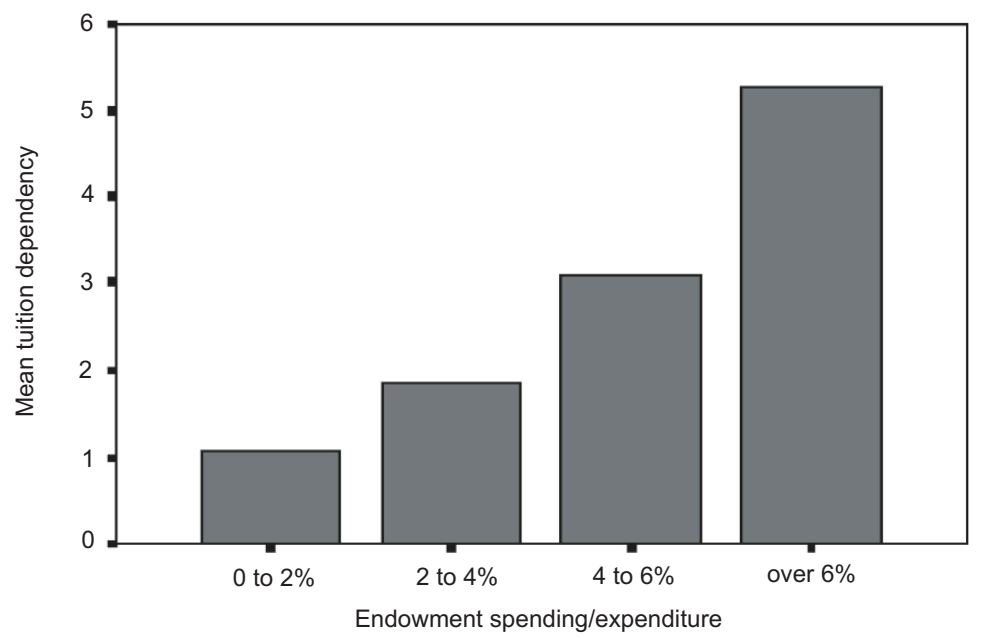

Figure 2: Tuition dependency as a function of endowment spending to expenditure ratio

relied upon 4 per cent or more of their operating revenue from endowment payouts had a decrease in tuition dependency ten years later. We can infer that institutions that had relied upon the annual fund too highly had a poorer match of the mission and the strategic plan than did schools with more of the operating budget covered by their endowments.

\section{Conclusion}

The findings of this study have significant implications for both short-term and longterm financial decision making. The results of the study are important because they offer a benchmark for setting the annual fund goal.

Understanding the long-term ramifications of overreliance on the annual fund will assist decision makers in setting the annual fund goal and provide a standard of accountability for decisions made regarding whether to spend now or save for the future. This will provide a basis for trustees and others to call into question the practice of arbitrarily raising the annual fund goal to balance the expenditure budget.

The authors hope that additional levels of scrutiny will preclude institutions from carelessly becoming financially vulnerable as evidenced by increased tuition dependency. This limits the parameters of what constitutes a reasonable annual fund goal. Although there may be several levels upon which reasonable people may disagree, this study found a statistically significant relationship between annual funds accounting for more than 4 per cent of the operating budget and increased tuition dependency 10 years later.

Essentially, a benchmark is provided for setting the annual fund goal. Exceeding the 4 per cent benchmark may raise a red flag for trustees and administrators as an augur of future tuition dependency. It establishes a means for judging whether an administration has an unhealthy bias for spending rather than saving and if it may 
be using the annual fund to accommodate its lack of austerity. This data can further help decision makers determine how comfortable they will be with a strong possibility of an increase in tuition dependency.

According to this study, depending on an institution's circumstances, the strategic planning horizon of its decision makers may not be appropriate. Presidents and their boards tend to spend money on current products rather than invest in endowments for the future. The benchmark is less important for institutions that are well endowed because they enjoy a high percentage of endowment payout to balance the budget. With a high endowment and a prudent spending policy, the ratio of endowment payout to expenses can be better managed for long-run financial equilibrium.

The benchmark can serve to justify pressure to increase the annual fund when it is significantly below the 4 per cent mark. It may also mitigate controversy regarding the budget process where the annual fund goal is in range of the benchmark. This study suggests that setting the annual fund goal should be a consideration in long-term strategic planning. In the course of strategic planning, decision makers must decide which direction their institution will take and what resources are needed to get them there. As indicated earlier in this study, institutions must grow to survive.

Future research should replicate this study by testing the same effects for private bachelor's institutions. The authors believe tests for bachelor's institutions would show even greater statistical significance, because they have greater revenue concentration, smaller breadth of programs, and the disparity of financial strengths is greater among the private liberal arts colleges.

As Massy points out, long-run financial equilibrium (LRFE) is an important aspect of planning and managing. ${ }^{15}$ LRFE requires three conditions: the current budget must be balanced, the growth rates of income and expenses must be sustainable, and there can be no hidden liabilities. Maintaining this equilibrium requires knowing or anticipating future revenue in relation to future expenditures.

Another aspect of equilibrium is derived from strategically planning the balance of each revenue source so that the growth rates of income and expense are sustainable. ${ }^{16}$ An important part of strategic planning involves anticipation of market changes. To the extent decision makers can project changes in the market, they should anticipate their revenue sources accordingly. For example, if an institution is projecting a trend in donor giving for nonbudget relieving capital projects and a decrease in giving for current operations, they should plan a future institutional budget that has greater dependence on tuition and/or endowment payout.

This trend is more than a hypothetical example. While total giving has increased, the percentage of gifts for current operations has been steadily decreasing for the last 15 years. ${ }^{17}$ By all accounts this trend will continue. A long-term implication of this study is that excessive reliance on the annual fund to meet current operations is a recipe for an increase in tuition dependency. Therefore, unless private master's institutions are comfortable projecting operating budgets with increased dependency on tuition, they would be well served by capping the level of their annual fund goal in their 
current budget process at a reasonable level and diverting surplus annual fund money into quasi-endowment.

\section{References}

1. R. L. Lenington (1966), Managing Higher Education as a Business, American Council on Education/Oryx Press, Phoenix, AZ, p. 9.

2. R. Zemsky and W. F. Massy (1995), "Expanding perimeters, melting cores and sticky functions toward an understanding of our current predicaments," Change, 27, pp. 41-9.

3. National Center for Education Statistics (2001), Post Secondary Education, Department of Education, Washington, DC, Chapter 3, Table 246.

4. W. F. Massy (1996), Resource Allocation in Higher Education, The University of Michigan Press, Ann Arbor.

5. D. B. Johnstone (1999), Financing Higher Education: Who Should Pay, Johns Hopkins University Press, Baltimore, p. 358.

6. P. A. Welch (1980), Annual Giving: An Overview, Josey-Bass, San Francisco.

7. P. F. Drucker (1990), Managing the Non-Profit Organization: Practices and Principles, Harper Collins, New York.
8. R. A. Lefrancois (1984), "Challenge for the 1980s: Productivity-oriented university management," Cost and Management, 58.

9. Massy (1996) Resource Allocation in Higher Education, op cit.

10. Lenington (1966), Managing Higher Education as a Business, op. cit.

11. Ibid., p. 85 .

12. H. Tuckman and C. Chang (1991), "A methodology for measuring the fiscal vulnerability of charitable nonprofit organizations," Nonprofit and Voluntary Sector Quarterly, 20, 4, pp. 445-60.

13. J. S. Greenlee and J. M. Trussel (2000), "Predicting the financial vulnerability of charitable organizations," Non-Profit Management and Leadership, 11, 2, pp. 199-211.

14. Council for Aid to Education (1992, 2001), Voluntary Support of Education, Council for Aid to Education, New York.

15. W. F. Massy (2003) "Rebuilding the University's Core Competency: Quality, Cost, and Technology in Higher Education," in W. F. Massy, Honoring The Trust: Quality and Cost Containment in Higher Education, Anker Publishing, Boston, MA.

16. Massy (1996) Resource Allocation in Higher Education, op. cit.

17. Council for Aid to Education (1998), Voluntary Support of Education, Council for Aid to Education, New York.

\section{Practitioner's Perspective}

Are master's universities with relatively robust annual funds that comprise 4 per cent or more of their operating budgets prone to become more tuition dependent over time? At first glance, the argument is counterintuitive, but that indeed is what Vincent Maniaci, Rob Poole, and Thomas L. Wilson argue in their study, "The Relationship of Annual Giving and Endowment Payout to Future Tuition Dependency at Private Master's Universities." Such an argument runs counter to the conventional wisdom, namely that a relatively large annual fund reduces the pressure for large tuition increases and even provides a foundation for endowment fund raising that is the ultimate protection against tuition dependency.

On closer examination, however, Maniaci, Poole, and Wilson are making a more fundamental argument. Their data indeed establishes an association between institutions whose annual funds were 4 per cent or more of their operating budget in 1992 and the tendency to become more tuition-dependent by 2001 . They also confirm the positive impact of strong endowments, documenting that institutions whose endowments contributed 4 per cent or more of their operating budget in 1992 proved to be less tuition-dependent in 2001. But their interpretation of these findings makes a crucial distinction in that they certainly do not oppose relatively large or growing annual funds. Instead they argue that strategically managed 
institutions should not turn to the annual fund as a short-term solution to longterm budgetary problems or as a short cut to balancing operating budgets that include wasteful spending. Annual fund goals, they argue, should not be set just "to plug a gap in the operating budget" or, even more dangerously, "to accommodate ... lack of austerity." The root problem with the never-ending pressure to increase annual fund goals, they correctly argue, is the propensity of most higher education administrators "to spend money on current products rather than invest in endowments for the future." Thus their most important conclusion, namely that substantial growth in annual funds should be directed to quasiendowment, not operations, as a long-term hedge against tuition dependency.

This insightful analysis is not only a message that higher education needs to hear and act upon but also is of heuristic importance in suggesting a whole new line of study with the potential to inform future institutional strategic planning. Among the 33 private master's universities with annual funds contributing 4 per cent or more to their operating budgets in 1992, surely not all of them became equally more tuition-dependent by 2001 . Even among those that did become more tuition-dependent, moreover, some did so because their academic excellence and resulting strong enrollments warranted substantially higher tuitions. The opportunity for future research, therefore, is to examine the cohort of institutions with traditionally strong annual funds to determine what impact the stewardship of these resources had in terms of academic excellence, reputation, enrollment, and endowment. While all of these institutions began in relatively the same position in terms of their strong annual funds, they may well have taken very different paths in building upon these annual funds and in advancing their positions in the higher education marketplace.

Three important recommendations for budgeting and strategic planning spring from Maniaci, Poole, and Wilson's research. First, annual fund goals should be set not only on the basis of short-term needs but also long-term implications. Second, funding more than 4 per cent of the operating budget from the annual fund is cause to sound the alarm. And finally, annual fund dollars, especially beyond 4 per cent of the operating budget, should be reserved for long-term use as quasiendowment. These recommendations are much needed in a prevailing environment of spending for the present rather than the future, an environment in which annual funds frequently are short-term budgetary fixes, and at a time when the call for taking a long-term perspective certainly is overdue. 